\title{
Desempenho produtivo, partenocarpia e expressão sexual de linhagens de pepino caipira em ambiente protegido
}

\author{
Amanda Regina Godoy; Márcia Maria Castro; Antonio Ismael Inácio Cardoso \\ UNESP-FCA, Dep ${ }^{\text {to }}$ Prod. Vegetal, C. Postal 237, 18603-970 Botucatu-SP; ar_godoy@ hotmail.com
}

\begin{abstract}
RESUMO
Avaliou-se a capacidade produtiva, partenocarpia e expressão sexual de linhagens de pepino caipira sob cultivo em ambiente protegido. A capacidade produtiva foi avaliada em experimento em blocos ao acaso com 18 tratamentos (16 linhagens e dois híbridos do tipo caipira, Safira e Guarani), quatro repetições e cinco plantas por parcela, em estufa agrícola com as laterais abertas possibilitando a entrada de insetos polinizadores. A expressão sexual e a partenocarpia foram avaliadas em delineamento semelhante, utilizando 16 linhagens da população SHS ( $\mathrm{F}_{2} \mathrm{RC}_{1}$ do cruzamento entre os híbridos Safira e Hatem (tipo holandês)) e 19 da população $\mathrm{GH}$ ( $\mathrm{F}_{2}$ do cruzamento entre os híbridos Guarani e Hatem), porém este experimento foi conduzido em estufa agrícola fechada, com tela anti-afídeo, evitando-se a entrada de insetos polinizadores. A partenocarpia foi avaliada verificando o pegamento de frutos em cada linhagem. Várias linhagens foram estatisticamente similares aos híbridos em termos de produção, mas nenhuma foi superior. Os híbridos Safira e Guarani produziram respectivamente 23,1 e 19,1 frutos planta $^{-1}$, sendo, respectivamente, 21,9 e 17,5 frutos comerciais. As massas total e comercial de frutos por planta foram respectivamente 3,8 e 3,6 kg para o híbrido Safira e 2,9 e 2,7 kg para o híbrido Guarani. A linhagem SHS-2 destacou-se pela boa produção, similar aos dois híbridos, apresentando frutos do tipo caipira claro, além de ser partenocárpica e possuir plantas ginóicas. Todas as linhagens da população SHS apresentaram frutos do tipo caipira, mas apenas cinco foram partenocárpicas. Na população $\mathrm{GH}$, nove linhagens foram partenocárpicas e dez apresentaram frutos do tipo caipira. Duas linhagens da população SHS apresentaram apenas plantas monóicas, com as demais segregando para plantas ginóicas e monóicas. Na população $\mathrm{GH}$, todas as plantas foram ginóicas. A população SHS é mais interessante para a obtenção de linhagens principalmente devido ao tipo de fruto caipira mais próximo dos frutos comerciais.
\end{abstract}

Palavras-chave: Cucumis sativus, produção, melhoramento de plantas.

\section{ABSTRACT}

Yield, parthenocarpy and sexual expression of 'caipira' cucumber lines under protected cultivation

The yield capacity, parthenocarpy and sexual expression of 'caipira' cucumber lines were evaluated under protected cultivation. Yield capacity was evaluated in an experiment in randomized blocks design with 18 treatments (16 lines and two 'caipira' hybrids, Safira and Guarani), four replicates and five plants per plot, in a greenhouse with opened laterals to permit the entrance of pollinators. Sexual expression and parthenocarpy were evaluated in similar design, with 16 lines of SHS population $\left(\mathrm{F}_{2} \mathrm{BC}_{1}\right.$ from the crossing between hybrids Safira and Hatem-beith alpha type) and 19 of $\mathrm{GH}$ population $\left(\mathrm{F}_{2}\right.$ from the crossing between hybrids Guarani and Hatem), but this experiment was set up in closed greenhouse, with anti-aphid net, avoiding the entrance of pollinators. Parthenocarpy was evaluated verifying fruit set in each line. Many lines were statistically similar to hybrids in yield capacity, but none was superior. Hybrids Safira and Guarani yielded 23.1 and 19.1 fruits plant $^{-1}$, and 21.9 and 17.5 commercial fruits, respectively. Total and commercial weights plant ${ }^{-1}$ were respectively 3.8 and $3.6 \mathrm{~kg}$ for hybrid Safira and 2.9 and $2.7 \mathrm{~kg}$ for hybrid Guarani. Line SHS-2 presented good yield, similar to both hybrids, with light 'caipira' fruit type, besides parthenocarpy and gynoecious plants. All lines from population SHS have 'caipira' fruit type, but only five were parthenocarpic. In population $\mathrm{GH}$, nine lines were parthenocarpic and ten have 'caipira' fruit type. Two lines from population SHS have only monoecious plants, with the others segregating to gynoecious and monoecious plants. In population $\mathrm{GH}$, all plants were gynoecious. SHS population is more interesting to obtain lines because the 'caipira' fruit type is more similar to commercial fruits.

Keywords: Cucumis sativus, yield, breeding.

(Recebido para publicação em 19 de novembro de 2007; aceito em 13 de maio de 2009) (Received in November 19, 2007; accepted in May 13, 2009)

$\mathrm{O}$ pepino (Cucumis sativus L.) é uma hortaliça pertencente à família Cucurbitaceae, com centro de origem na Índia. A espécie não se adapta ao cultivo sob baixas temperaturas, sendo o desenvolvimento da planta favorecido por temperaturas superiores a $20^{\circ} \mathrm{C}$ (Lower \& Edwards, 1986). Temperaturas inferiores a $20^{\circ} \mathrm{C}$ afetam a absorção de água e nutrientes pelo sistema radicular (Robinson \& Decker-Walters, 1999), fato que tem contribuído para o cultivo em ambiente protegido. Neste tipo de culti- vo, o pepino se encontra entre as principais hortaliças, ocupando o segundo lugar, após o tomate (Cañizares, 1998). Aumentos de produtividade sob este sistema de cultivo em relação ao cultivo em campo aberto, têm sido relatados no Brasil, variando de 0,3 a 48,5\%, dependendo da cultivar (Reis et al., 1991, 1992) e de 55,0 a 79,6\% (Oliveira et al., 1995).

A maioria dos híbridos de pepino do tipo japonês e holandês são partenocárpicos, por isso podem ser cultivados em ambiente protegido o ano todo (Filgueira, 2000; Cardoso \& Silva, 2003). As cultivares e híbridos de pepino caipira não apresentam partenocarpia, o que dificulta o seu plantio em estufas fechadas, devido à redução na possibilidade de entrada de insetos polinizadores (Cardoso, 2002; Godoy \& Cardoso, 2004). Entretanto, muitos produtores têm cultivado pepino em estufas, mantendo as laterais abertas e possibilitando a entrada destes insetos.

A partenocarpia viabiliza a tecnologia de produção de pepino em estufa ga- 
rantindo a produtividade e a qualidade de frutos na ausência de insetos polinizadores. Esta é uma característica vantajosa, que pode ser incorporada às plantas através do melhoramento genético. Outra importante característica que vem sendo trabalhada nos programas de melhoramento genético de pepino é o ginoicismo, visto que plantas ginóicas têm maior potencial de produção (Denna, 1973; Miller, 1976; Wehner \& Miller, 1985). Entretanto, somente a incorporação destas características não é suficiente. A população resultante tem que ser adaptada ao cultivo sob ambiente protegido e, de preferência, ser competitiva em relação aos híbridos comerciais, mesmo na presença de insetos polinizadores. A obtenção de linhagens ginóicas também facilita a produção comercial de sementes de híbridos $\mathrm{F}_{1}$ (Zhang et al., 1992).

Linhagens puras, vigorosas e sadias são condições básicas para viabilizar o programa de produção de híbridos e, para serem obtidas com probabilidade aceitável, deve-se partir de populações geneticamente adequadas (Vello, 1984). Segundo Fehr (1987), a avaliação do desempenho das linhagens per se obtidas a partir de populações segregantes é uma das fases para o desenvolvimento de híbridos comerciais. Já Robinson (1999) relatou que a ausência de perda de vigor pela endogamia poderia viabilizar a utilização de linhagens de pepino diretamente como cultivares comerciais.

Este trabalho teve como objetivo avaliar a capacidade produtiva, partenocarpia e expressão sexual de linhagens de pepino caipira cultivadas em ambiente protegido.

\section{MATERIAL E MÉTODOS}

Os experimentos foram conduzidos na Fazenda Experimental São Manuel da UNESP, Campus de Botucatu. Foram utilizadas estufas agrícolas, tipo arco, com $7 \mathrm{~m}$ de largura por $20 \mathrm{~m}$ de comprimento e pé direito de $1,8 \mathrm{~m}$, com cobertura de polietileno transparente de $75 \mu \mathrm{m}$ de espessura.

Foram utilizadas duas populações, a primeira obtida através do cruzamento entre os híbridos Safira (tipo caipira) e
Hatem (tipo holandês ou beit alpha). O híbrido resultante foi retrocruzado com a cultivar híbrida Safira, obtendo-se a população (Safira x Hatem) x Safira $\mathrm{F}_{1} \mathrm{RC}_{1}$. Vinte plantas desta população foram cruzadas entre si para obtenção da população $\mathrm{F}_{2} \mathrm{RC}_{1}$, denominada de população SHS. A segunda população foi obtida através do cruzamento entre os híbridos Guarani (tipo caipira) e Hatem, resultando na população (Guarani x Hatem) F $F_{1}$. Vinte plantas desta população foram cruzadas entre si para obtenção da população $\mathrm{F}_{2}$, denominada de população GH. A partir de autofecundações sucessivas destas duas populações (SHS e GH), pelo método de Single Seed Descent (SSD) (Brim, 1966), foram obtidas as linhagens que constituíram os tratamentos avaliados. Todos os cruzamentos manuais foram realizados fechando-se as flores femininas antes de sua antese e polinizando-as manualmente na manhã seguinte com pólen das flores masculinas. Após a polinização, as flores foram protegidas com sacos de papel (Lower \& Edwards, 1986).

O híbrido Hatem foi utilizado por apresentar forte partenocarpia, ser adaptado ao cultivo em ambiente protegido e apresentar frutos com dimensões e coloração mais próximas do tipo caipira que os híbridos partenocárpicos do tipo japonês. Porém, não foi utilizado como testemunha por não haver disponibilidade de sementes.

Experimento 1: foi implantado no delineamento de blocos ao acaso, com dezoito tratamentos (dezesseis linhagens da população SHS e dois híbridos comerciais: Safira e Guarani), quatro repetições e cinco plantas por parcela. A semeadura foi realizada em bandejas de poliestireno expandido de 128 células (03 de agosto de 2004) e, o transplante, quando as plântulas apresentavam duas folhas definitivas (26 de agosto). As plântulas foram transplantadas para estufas agrícolas, sem fechamento das laterais para permitir a entrada de insetos polinizadores. O espaçamento utilizado foi $1,0 \times 0,5 \mathrm{~m}$.

A colheita estendeu-se de 08 de outubro a 22 de novembro de 2004 . Os frutos foram colhidos a cada dois dias, com cerca de $15 \mathrm{~cm}$ de comprimento, pesa- dos e classificados em comerciais ou não, de acordo com a ausência ou presença de defeito visual aparente.

Avaliou-se massa e número total de frutos e de frutos comerciais, porcentagem de frutos comerciais e massa média de frutos comerciais. Foram realizadas análises de variância e as médias foram comparadas pelo teste de Tukey $(\mathrm{p}<0,05)$.

Experimento 2: Foram avaliadas, para partenocarpia e expressão sexual, dezesseis linhagens da população SHS, dezenove linhagens da população $\mathrm{GH}$ e os híbridos comerciais Safira e Guarani. O delineamento utilizado foi blocos ao acaso, com quatro repetições e cinco plantas por parcela.

A semeadura foi realizada em bandejas de poliestireno expandido de 128 células (03 de agosto de 2004) e, o transplante, quando as plântulas apresentavam duas folhas definitivas (26 de agosto). O espaçamento utilizado foi $1,0 \times 0,5$ m. Para avaliar a partenocarpia, as plantas foram colocadas em estufa agrícola totalmente fechada, com tela anti-afídeo, evitando-se a entrada de insetos polinizadores (Pike \& Peterson, 1969). A partenocarpia foi avaliada verificando o pegamento de frutos nas plantas de cada linhagem. Os frutos foram colhidos e avaliados buscando verificar se poderiam ser classificados como tipo caipira (formato cilíndrico e cor verde-clara).

A expressão sexual foi avaliada com o início do florescimento, através da observação da presença de flores femininas e masculinas na haste principal da planta. Plantas que apresentaram somente flores femininas foram classificadas como ginóicas, enquanto plantas com flores femininas e masculinas foram classificadas como monóicas. Em ambos os experimentos, durante a condução da cultura, a área foi mantida livre de ervas daninhas através de capinas manuais. As plantas foram irrigadas por gotejamento. A adubação de cobertura foi efetuada semanalmente com nitrato de cálcio $\left(2 \mathrm{~g} \mathrm{planta}^{-1}\right)$ a partir da primeira semana após o transplante e nitrato de potássio (3 g planta $\left.^{-1}\right)$ a partir do início da frutificação. $O$ controle de pragas e doenças foi realizado de acordo com as necessidades da cultura, através de pulverizações com inseticidas e fungicidas. 
Tabela 1. Produção total e comercial de frutos de pepino (total and commercial yield of cucumber fruits). São Manuel, UNESP-FCA, 2004.

\begin{tabular}{|c|c|c|c|c|c|c|}
\hline Genótipos & $\begin{array}{c}\mathrm{NFT}^{1} \\
\text { planta-1 }^{-1}\end{array}$ & $\begin{array}{c}\text { NFC }^{1} \\
\text { planta-1 }^{-1}\end{array}$ & $\begin{array}{c}\text { MT }^{1} \text { planta } \\
{ }^{1}(\mathrm{~kg})\end{array}$ & $\begin{array}{c}\text { MC }^{1} \text { planta } \\
{ }_{1} \text { (kg) }\end{array}$ & MMC1 (g) & $\% \mathrm{FC}^{1}$ \\
\hline SHS-1 & $16,3 \mathrm{bc}$ & $15,3 \mathrm{bc}$ & $2,6 \mathrm{c}$ & $2,5 \mathrm{c}$ & $160,5 \mathrm{ab}$ & $93,4 \mathrm{ab}$ \\
\hline SHS-2 & 25,0 a & $23,2 \mathrm{a}$ & $4,0 \mathrm{a}$ & 3,7 a & $161,2 a b$ & $92,6 a b$ \\
\hline SHS-3 & $19,8 \mathrm{abc}$ & $18,1 \mathrm{abc}$ & $3,3 a b c$ & $3,1 \mathrm{abc}$ & $171,3 a b$ & $90,7 a b$ \\
\hline SHS-4 & $19,3 \mathrm{abc}$ & $18,7 \mathrm{abc}$ & $3,3 \mathrm{abc}$ & $3,2 \mathrm{abc}$ & $171,9 a b$ & 96,6 a \\
\hline SHS-5 & $15,3 \mathrm{c}$ & $14,2 \mathrm{c}$ & $2,4 \mathrm{c}$ & $2,2 \mathrm{c}$ & $160,5 \mathrm{ab}$ & $92,9 a b$ \\
\hline SHS-6 & $17,7 \mathrm{abc}$ & $16,3 \mathrm{abc}$ & $3,0 \mathrm{abc}$ & $2,8 \mathrm{abc}$ & $170,0 \mathrm{ab}$ & $91,6 a b$ \\
\hline SHS-7 & $18,4 a b c$ & $17,3 \mathrm{bc}$ & $3,1 \mathrm{abc}$ & $2,9 a b c$ & $169,1 \mathrm{ab}$ & $94,1 \mathrm{ab}$ \\
\hline SHS-8 & $15,8 \mathrm{bc}$ & $14,9 \mathrm{bc}$ & $2,5 \mathrm{c}$ & $2,4 \mathrm{c}$ & $158,7 \mathrm{ab}$ & $94,4 a b$ \\
\hline SHS-9 & $19,0 \mathrm{abc}$ & $16,6 \mathrm{abc}$ & $3,0 \mathrm{abc}$ & $2,7 \mathrm{abc}$ & $161,1 \mathrm{ab}$ & $87,1 \mathrm{~b}$ \\
\hline SHS-10 & $18,5 \mathrm{abc}$ & $17,9 \mathrm{abc}$ & $3,2 \mathrm{abc}$ & $3,1 \mathrm{abc}$ & $172,9 a b$ & 96,5 a \\
\hline SHS-11 & $19,2 \mathrm{abc}$ & $18,1 \mathrm{abc}$ & $3,3 \mathrm{abc}$ & $3,2 \mathrm{abc}$ & $178,3 \mathrm{a}$ & $94,2 a b$ \\
\hline SHS-12 & $19,8 \mathrm{abc}$ & $18,7 \mathrm{abc}$ & $3,1 \mathrm{abc}$ & $2,9 a b c$ & $155,9 a b$ & $94,0 \mathrm{ab}$ \\
\hline SHS-13 & $16,4 \mathrm{bc}$ & $14,3 \mathrm{c}$ & $2,6 \mathrm{c}$ & $2,3 c$ & $160,5 a b$ & $87,5 \mathrm{~b}$ \\
\hline SHS-14 & $17,2 \mathrm{bc}$ & $16,3 \mathrm{abc}$ & $2,7 \mathrm{bc}$ & $2,5 \mathrm{c}$ & 154,7 b & $94,7 a b$ \\
\hline SHS-15 & $17,7 \mathrm{abc}$ & $16,9 a b c$ & $2,9 \mathrm{abc}$ & $2,8 \mathrm{abc}$ & $162,8 a b$ & $94,7 a b$ \\
\hline SHS-16 & $19,1 \mathrm{abc}$ & $17,7 \mathrm{abc}$ & $2,9 \mathrm{abc}$ & $2,8 \mathrm{abc}$ & $157,0 \mathrm{ab}$ & $92,8 \mathrm{ab}$ \\
\hline Safira & $23,1 a b$ & $21,9 a b$ & $3,8 a b$ & $3,6 a b$ & $165,5 a b$ & $94,5 a b$ \\
\hline Guarani & $19,1 \mathrm{abc}$ & $17,5 \mathrm{abc}$ & $3,0 \mathrm{abc}$ & $2,7 \mathrm{abc}$ & $159,5 a b$ & $91,8 a b$ \\
\hline C.V. (\%) & 15,7 & 16,2 & 14,5 & 15,2 & 5,4 & 3,3 \\
\hline
\end{tabular}

Médias seguidas de mesma letra nas colunas não diferem estatisticamente entre si, teste de Tukey, $\mathrm{p}<0,05$ (Means followwed by same letter in colums did not differ statisticaly each other, Tukey test, $\mathrm{p}<0,05)$.

$1 / \mathrm{NFT}=$ número total de frutos (total fruit number); NFC $=$ número de frutos comerciais (commercial fruit number); MT = massa total de frutos (total weight of fruits); $\mathrm{MC}=$ massa de frutos comerciais (weight of commercial fruits); MMC = massa média de frutos comerciais (average weight of commercial fruits); $\% \mathrm{FC}=$ porcentagem de frutos comerciais (percentage of commercial fruits).

Cada planta foi tutorada individualmente eliminando todas as brotações e flores até $\mathrm{o} 5^{\circ}$ nó da haste principal. Realizou-se também a desbrota das ramas laterais (após o $6^{\circ}$ nó da haste principal), entre a segunda e terceira folhas. Retirou-se o meristema apical da planta quando esta atingiu a altura do arame (cerca de 1,80 m).

\section{RESULTADOS E DISCUSSÃO}

Experimento 1: Várias linhagens experimentais apresentaram resultados similares ao híbrido Safira e todas elas foram estatisticamente semelhante ao híbrido Guarani, em todas as características avaliadas (Tabela 1). O híbrido Safira teve um número total de frutos estatisticamente superior apenas à linhagem SHS-5, maior número de frutos comerciais que as linhagens SHS-5e SHS-13, maior massa total de frutos por planta que as linhagens SHS-1, SHS-5, SHS-8 e
SHS-13 e para massa comercial de frutos por planta, foi superior às linhagens SHS-1, SHS-5, SHS-8, SHS-9 e SHS- 13. Godoy et al. (2005), ao estudarem a mistura de linhagens desta mesma população com uma a cinco gerações de autofecundação, relataram perda de vigor associada à endogamia, mostrando a dificuldade de se obter linhagens nesta população por SSD com potencial produtivo superior à população original. Porém, os autores avaliaram populações obtidas pela mistura de linhagens e conforme Maluf (2001), diferentes linhas obtidas após certo número de gerações de autofecundação, podem apresentar resultados diferentes em relação à perda de vigor, como sugerem os resultados aqui obtidos.

Neste trabalho, tomou-se uma amostra das linhagens obtidas nos cruzamentos e cada uma foi avaliada individualmente. Embora algumas tenham sido menos produtivas que os híbridos parentais, foram obtidas outras tão produtivas quanto eles. Destaque deve ser dado à linhagem SHS-2, partenocárpica, com frutos do tipo caipira claro, apresentando plantas ginóicas que podem ser selecionadas em um teste de progênie. A boa produtividade desta linhagem confirma que linhagens que não apresentam perda de vigor pela endogamia poderiam ser utilizadas diretamente como cultivares de pepino (Robinson, 1999). Porém, na combinação entre as linhagens para obtenção de híbridos $F_{1}$ podem ser obtidos híbridos experimentais ainda mais produtivos, tendo-se em vista que diversos autores relataram a presença de heterose para produção de frutos em pepino (Ghaderi \& Lower, 1978; Delaney \& Lower, 1987; Robinson \& Decker-Walters, 1999; Cardoso, 2006, 2007; Godoy et al., 2008).

Os valores obtidos para as características de produção por planta foram um pouco inferiores para produção total (3,8 kg planta ${ }^{-1}$ para o híbrido Safira) e muito superiores para produção comercial (3,6 kg para o híbrido Safira) (Tabela 1), que o relatado por Cardoso (2002) no cultivo de inverno em São Manuel, onde as produções total e comercial do híbrido Safira foram respectivamente 3,5 e $2,6 \mathrm{~kg}$ planta $^{-1}$. A maior produção comercial aqui observada pode ser resultado da boa sanidade da cultura. Exceto pela linhagem SHS-5, nenhuma outra foi inferior ao híbrido comercial, tendo sido sempre observados valores superiores a $87 \%$ da produção total sendo classificada como comercial (Tabela 1), enquanto Cardoso (2002) obteve apenas cerca de $64 \%$ de frutos comerciais com o híbrido Safira.

Para as características massa média de frutos comerciais e porcentagem de frutos comerciais, não houve qualquer diferença significativa entre os híbridos Safira e Guarani e as linhagens avaliadas. Para massa média de frutos comerciais, a única diferença estatística observada foi a superioridade da linhagem SHS-11 sobre a linhagem SHS-14 (Tabela 1). A ausência de diferença significativa para esta característica entre os diferentes materiais aconteceu em virtude da pequena variação observada na massa média de frutos comerciais (155 a 178 $\mathrm{g}_{\text {fruto }^{-1}}$ ) e já era esperada. O ponto de 
colheita foi aproximadamente o mesmo para todos os tratamentos, ou seja, frutos com cerca de $15 \mathrm{~cm}$ de comprimento. O pepino é um fruto imaturo, ainda em fase inicial de crescimento. Diferenças na massa média dos frutos entre os materiais avaliados seriam facilmente obtidas se os frutos fossem colhidos maduros, com o máximo de seu tamanho.

Experimento 2: Das 16 linhagens da população SHS avaliadas, apenas cinco (31,3\%) foram partenocárpicas. A baixa taxa de linhagens partenocárpicas deveu-se provavelmente ao retrocruzamento realizado com um parental não partenocárpico (híbrido Safira). Segundo Allard (1971), o método do retrocruzamento constitui uma maneira precisa de melhorar cultivares que já são superiores em relação a grande número de atributos, mas que ainda apresentam deficiência em algumas características. No presente estudo, o retrocruzamento objetivou recuperar as características do fruto do tipo caipira, o que realmente foi observado, já que todas as linhagens apresentaram frutos do tipo caipira.

Já entre as 19 progênies da população $\mathrm{GH}$, nove $(47,4 \%)$ foram partenocárpicas. Entretanto, quanto às características de fruto, houve linhagens com frutos do tipo caipira, linhagens com fruto do tipo holandês e linhagens que ainda estão segregando para tipo de fruto. Neste caso, a não realização do retrocruzamento para o híbrido Guarani favoreceu o aumento da taxa de linhagens partenocárpicas (sem retrocruzamento para parental não partenocárpico), mas desfavoreceu a recuperação do tipo de fruto caipira, inviabilizando o aproveitamento das linhagens para o mercado de pepino caipira.

Como o avanço de gerações foi realizado por SSD, sem seleção para partenocarpia, as proporções de progênies partenocárpicas obtidas (31,3\% para SHS e $47,4 \%$ para $\mathrm{GH}$ ) se aproximam do esperado (25\% e $50 \%$, respectivamente, com e sem retrocruzamento para o parental não partenocárpico) considerando a herança da característica. Segundo Pike \& Peterson (1969), a herança da partenocarpia é condicionada por um gene $(\mathrm{P})$, que apresenta dominância incompleta.
Quanto à expressão sexual, observou-se que a maioria das linhagens da população SHS apresentou segregação para plantas ginóicas e monóicas e apenas duas linhagens apresentaram apenas plantas monóicas. Provavelmente o híbrido Safira vem de um cruzamento entre um parental ginóico e um monóico. A segregação observada em algumas linhagens sugere que a característica ainda não foi fixada. A expressão sexual ginóica é condicionada por um gene $\mathrm{F}$, que sofre considerável influência de genes modificadores e de fatores ambientais (Cantliffe, 1981; Lower et al., 1975). Deve-se ressaltar também que no processo de autofecundações sucessivas é mais fácil manter plantas monóicas que plantas ginóicas, mesmo com a aplicação de tiossulfato de prata (Godoy $e t$ al., 2005), pois, para se realizar a autofecundação, é necessário que, no mesmo dia, na mesma planta, ocorra a antese tanto de uma flor feminina como de uma masculina. Se isto não ocorrer, não se realiza a autofecundação e a planta não deixa descendentes para a próxima geração por SSD. Plantas fortemente ginóicas, mesmo com aplicação de tiossulfato de prata, às vezes não emitem ou emitem um pequeno número de flores masculinas, impossibilitando a autofecundação. Ao contrário da população SHS, todas as plantas das linhagens da população GH foram ginóicas. Embora sua identificação seja um sigilo comercial, provavelmente ambos os parentais do híbrido Guarani são ginóicos não possibilitando a segregação para plantas monóicas.

Plantas ginóicas e partenocárpicas viabilizam a tecnologia de produção de pepino em estufa garantindo a produtividade e qualidade de frutos na ausência de insetos polinizadores. Percebe-se que existe um grande número de linhagens com ambas características, sendo cinco da população SHS (SHS-1, SHS-2, SHS-3, SHS-5 e SHS-9) e cinco da GH (GH-9, GH-10, GH-12, GH-14 e GH-18) que devem ser avaliadas para potencial produtivo na ausência de insetos polinizadores. Porém, a população SHS mostrou-se mais interessante para a obtenção de linhagens que a população $\mathrm{GH}$, principalmente devido ao tipo de fruto caipira observado em suas linha- gens serem mais próximos do padrão comercial.

\section{REFERÊNCIAS}

ALLARD RW. 1971. Princípios do melhoramento genético das plantas. São Paulo: Edgard Blücher. 381 p.

BRIM CA. 1966. A modified pedigree method of selection in soybeans. Crop Science 6: 220.

CAÑIZARES KAL. 1998. A cultura de pepino. In: GOTO R; TIVELLI SW. (eds) Produção de hortaliças em ambiente protegido: condições subtropicais. São Paulo: Fundação Editora UNESP. p.195223.

CANTLIFFE DJ. 1981. Alteration of sex expression in cucumber due to changes in temperature, light intensity and photoperiod. Journal of American Society of Horticultural Science 106: 133-136.

CARDOSO AII. 2002. Avaliação de cultivares de pepino tipo caipira sob ambiente protegido em duas épocas de semeadura. Bragantia 61: 43-48.

CARDOSO AII. 2006. Dialelo entre linhagens de uma população de pepino tipo 'Caipira'. Horticultura Brasileira 24: 259-263.

CARDOSO AII. 2007. Avaliação de linhagens e híbridos experimentais de pepino do grupo varietal japonês sob ambiente protegido. Bragantia 66: 473-479.

CARDOSO AII; SILVA N. 2003. Avaliação de híbridos de pepino do tipo japonês sob ambiente protegido em duas épocas de cultivo. Horticultura Brasileira 21: 170175.

DELANEY DE; LOWER RL. 1987. Generation means analysis of plant characters in crosses between two determinate cucumber lines and Cucumis sativus var. hardwickii. Journal of the American Society for Horticultural Science 112; 707-711.

DENNA DW. 1973. Effects of genetic parthenocarpy and gynoecious flowering habitat on fruit production and growth of cucumber (Cucumis sativus L.). Journal of the American Society for Horticultural Science 98: 602-604.

FEHR WR. 1987. Principles of cultivar development: theory and thecnique. New York: Mcmillan Publishing Co. 536p.

FILGUEIRA FAR. 2000. Novo manual de olericultura: agrotecnologia moderna na produção e comercialização de hortaliças. Viçosa: Editora UFV. 402p.

GHADERI A; LOWER RL. 1978. Heterosis and phenotypic stability of F1 hybrids in controlled environment. Journal of the American Society for Horticultural Science 103: 275-278.

GODOY AR; CARDOSO AII. 2004. Pegamento de frutos em pepino caipira não partenocárpico sob cultivo protegido com aplicação de ácido naftaleno acético. Bragantia 63: 25-29. 
GODOY AR, HIGUTI ARO, CARDOSO AII. 2008. Produção e heterose em cruzamentos entre linhagens de pepino do grupo caipira. Bragantia 67: 817-825.

GODOY AR; OVIEDO VRS; CARDOSO AII. 2005. Análise endogâmica de uma população de pepino caipira. Horticultura Brasileira 23: 785-788.

LOWER RL; EDWARDS MD. 1986. Cucumber breeding. In: BASSET MJ (ed) Breeding vegetable crops. Westport: Avi Publishing. p.173-207.

LOWER RL; McCREIGHT JD; SMITH OS. 1975. Photoperiod and temperature effects on growth and sex expression of cucumber. Hortscience 10: 318.

MALUF WR. 2001. Heterose e emprego de híbridos $\mathrm{F}_{1}$ em hortaliças. In: NASS, LL et al. (eds) Recursos genéticos $e$ melhoramento: plantas. Rondonópolis: Fundação MT. p.327-356.

MILLER CH. 1976. Effects of blending gynoecious and monoecious cucumber seeds on yield patterns. HortScience 11: 428-430.
OLIVEIRA ACB; ARAUJO ML; LEAL NR. 1995. Avaliação do comportamento de três cultivares de pepino submetidas ao cultivo sob estrutura de proteção e a céu aberto na região Norte Fluminense-RJ. Horticultura Brasileira 13: 99.

PIKE LM; PETERSON CE. 1969. Inheritance of parthenocarpy in the cucumber (Cucumis sativus L.). Euphytica 18: 101105.

REIS NVB; HORINO Y; OLIVEIRA CAS; BOITEUX LS. 1991. Influência da radiação fotossinteticamente ativa (RFA) sobre os componentes de produção de nove genótipos de pepino plantado a céu aberto e sob estufas plásticas. Horticultura Brasileira 9: 55.

REIS NVB; HORINO Y; OLIVEIRA CAS; BOITEUX LS; LOPES JF. 1992. Influência de temperatura - graus-dia - sobre a produção de pepino sob cultivo protegido e a céu aberto. Horticultura Brasileira 10: 65.
ROBINSON RW. 1999. Rationale and methods for producing hybrid cucurbit seed. Journal of New Seeds 1: 1-47.

ROBINSON RW; DECKER-WALTERS DS. 1999. Cucurbits. Cambridge: CAB International. 226p.

VELLO NA. 1984. Endogamia. Piracicaba: ESALQ. 29p.

WEHNER TC, MILLER CH. 1985. Effect of gynoecious expression on yield and earliness of a fresh-market cucumber hybrid. Journal of the American Society for Horticultural Science 110: 464-466.

ZHANG Q; GABERT AC; BAGGETT JR. 1992. Parents and mating systems affect the transfer of gynoecious flowering to chinese monoecious cucumbers. Journal of the American Society for Horticultural Science 117: 515-517. 